\title{
Integrated HPS? Formal versus historical approaches to philosophy of science
}

\author{
Bobby $\operatorname{Vos}^{1}$
}

Received: 19 April 2021 / Accepted: 25 September 2021 / Published online: 7 December 2021

(c) The Author(s) 2021

\begin{abstract}
The project of integrated HPS ('integrated history and philosophy of science') has occupied philosophers of science in one form or another since at least the 1960s. Yet, despite this substantial interest in bringing together philosophical and historical reflections on the nature of science, history of science and formal philosophy of science remain as divided as ever. In this paper, I will argue that the continuing separation between historical and formal philosophy of science is ill-founded. I will argue for this in both abstract and concrete terms. At the abstract level, I reconstruct two possible arguments for the incompatibility of historical and formal philosophy of science and argue that they are both wanting. At the concrete level, I discuss how historical and formal philosophy of science have been brought together in practice, namely: in the form of a largely forgotten research tradition that I will refer to here as the study of formalized macro-units. After a brief exposition, I argue that this research tradition has been unduly overlooked by historically minded philosophers of science. Bringing together these observations, I argue that the divide between historical and formal philosophy of science is not grounded in any substantive arguments, but can be primarily attributed to disciplinary happenstance.
\end{abstract}

Keywords Formal methods · History · Integrated HPS · Structuralism

\section{Introduction: formalism versus history}

The prospects of integrated history and philosophy of science-or Integrated HPS, for short-have been discussed by philosophers since at least the $1960 \mathrm{~s}$, when the

This article belongs to the topical collection "Metaphilosophy of Formal Methods", edited by Samuel Fletcher.

$凶$ Bobby Vos

bfmv2@cam.ac.uk

1 Department of History and Philosophy of Science, University of Cambridge, Cambridge,

Cambridgeshire, UK 
publication of Kuhn's Structure brought about the historical turn in the philosophy of science. ${ }^{1}$ In this paper, I want to discuss the prospects for integrating history of science with a specific subfield of philosophy of science, viz. formal philosophy of science. ${ }^{2}$ Despite the near 6 decades' worth of reflections on Integrated HPS (both hopeful and pessimistic), the prospects for integrating history of science with formal philosophy of science have received virtually no substantial discussion in the literature. ${ }^{3}$ Initially, this might strike one as rather unsurprising. After all, was it not the point of the historical turn and the subsequent rise of historically informed philosophy of science that we could finally break free from the formalist straitjacket forced upon us by the logical empiricists? This, indeed, would appear to be the received view:

[Feyerabend, Hanson, Kuhn, and others] view theories as deep conceptual systems which provide a Weltanschauung, or perspective, for viewing the world. As such, theories are viewed as essentially dynamic, growing entities, and it is maintained that theories cannot be understood if divorced from the dynamics of their developments. These authors implicitly seem to take this as showing that formalization of theories is inappropriate in a philosophical analysis of theories (Suppe 1977, p. 114).

[More and more people, following Kuhn and, especially, Feyerabend] say, the 'logical point of view' is inappropriate, or, at best, inadequate (to the extent of being useless). The scientific reality one should be concerned with is either too 'dynamic', or too 'complex' to be captured by formal tools (Van Benthem 1982, p. 432).

The majority of the philosophers of science who were sensitive to the historicist perspective concluded that the complexity and richness of the elements involved in science, escaped any attempt at formalization... This is the antiformalist moral that spread in many metascientific environments after the historicist revolt (Lorenzano 2010, sec. 1.2.4), original italics.

In light of these quotations, one might be forgiven for considering the very notion of an 'integrated history and formal philosophy of science' (or, for short: Integrated $H F S$ ) to be a contradiction in terms.

As announced, the aim of this paper is to argue for the viability of Integrated HFS. To this end, it will be important to make clear exactly what we take Integrated HFS to

\footnotetext{
1 Prior to the twentieth century, early philosophers of science, including Mach, Duhem and Whewell, similarly drew on historical considerations in expounding their philosophical accounts. I will not consider this tradition of 'historical philosophy of science' here. For more comprehensive surveys of the relation between history of science and philosophy of science, cf. Nickles (1995) and Miller (2012).

2 I take 'formal philosophy of science' to mean any approach to doing philosophy of science that substantially involves the use of formal methods, including (for example) methods from logic, game theory, probability theory, statistics, set theory and category theory. Cf. Horsten and Douven (2008), Müller (2010) for a history and overview of the use of formal methods in philosophy of science.

3 There are some notable exceptions, though, as mentioned in footnote 6 . But even in these exceptional cases, the discussion is focused more on the application of particular formal methods to historical philosophy of science than on the synthesis of these two strands of philosophy of science in general. This stands in stark contrast to the plethora of general, methodological reflections on Integrated HPS that exist in the literature today (see footnotes 8 and 13 for a sampling of these methodological debates).
} 
consist in. I do so explicitly in Sect. 2. As we will see there, spelling this out will go a long way to dissolving the apparent tension between formalism and history expressed in the above quotations. For the moment, let us simply construe Integrated HFS as any formal analysis of science that draws on the history of science in a substantial way.

The plan for the paper is as follows. I start in Sect. 2 by reconstructing-for lack of an explicit argument in the literature-two possible arguments for the perceived dichotomy between history and formalism (the $H / F$ dichotomy) and arguing that the reconstructed arguments ultimately fall flat. ${ }^{4}$ In doing so, I will argue that there are at least three different types of Integrated HPS, and, by extension, three possible construals of Integrated HFS. ${ }^{5}$

Having argued for the viability of Integrated HFS in principle, the next two sections are dedicated to an example of Integrated HFS in practice. More specifically, I discuss a largely forgotten metascientific research tradition, which I refer to as the study of formalized macro-units (FMU). This research tradition, which had its heyday in the 1970s and ' 80 s, remains to my knowledge one of the few substantial forays into Integrated HFS. ${ }^{6}$ In Sect. 3, I present a brief overview of FMU. In particular, I discuss the two strands of formal philosophy that together constitute this research tradition, to wit: the Munich school of structuralism and its formalization of Kuhn's concept of paradigm (Sect. 3.1) and David Pearce and Veikko Rantala's abstract logic approach to scientific theories, and their attendant concept of theory-ensemble (Sect. 3.2). In Sect. 4, I subvert criticisms that would claim that FMU is of no use to the historically minded philosopher of science. I do so by showing how FMU emerged in direct response to problems that plagued historical analyses of science in the post-positivist era. The upshot is that the idea of Integrated HFS is not confined to the realm of idle hypotheticals, but has been actively put into practice. Bringing together the above observations, I conclude that there is no substantive argument for the $\mathrm{H} / \mathrm{F}$ dichotomy.

In Sect. 5, I speculate about why the H/F dichotomy nevertheless appears to be so widespread a feature of contemporary history and philosophy of science. Building on a similar diagnosis by Christian Damböck (2014), I argue that the dichotomy may be

\footnotetext{
4 These need not be the only arguments against the H/F dichotomy. They are, however, the arguments that seem to me (i) the most prima facie plausible arguments for the H/F dichotomy and (ii) the arguments that are most likely to be invoked, should one press the proponents of this dichotomy for explicit argumentation.

5 Schickore (2018, pp. 92-93), in discussing Laudan (1981), similarly distinguishes five different types of historical philosophy of science. For the relation between my division and the one put forth by Schickore, see footnote 21.

6 Roughly speaking, we may situate FMU within a wider strand of formal philosophy of science that concerns itself with the formal structure of scientific knowledge. Other strands of formal philosophy of science have also engaged with the historical dimension of science in their own ways. In particular, we find a rich engagement with the history of science in the strand of philosophy concerned with the formal structure of scientific inference, particularly Bayesian epistemology; see e.g. Salmon (1970, 1990) and Earman (1992, ch. 8). In addition, authors working in computational philosophy of science, particularly agent-based modelling, have similarly engaged with the historical dimension of science, at times explicitly connecting their work to considerations in Integrated HPS; see e.g. Frey and Šešelja (2018). Due to limitations of space (as well as my own expertise), I will not discuss these different manifestations of Integrated HFS in the present paper. Suffice it to say, the existence of these additional strands of research only provides more grist to the mill of the proponent of Integrated HFS. I thank Dunja Šešelja and an anonymous reviewer for pressing me on the relevance of these additional strands of research for my discussion.
} 
attributed to disciplinary happenstance. Finally, I reflect on the prospects of Integrated HFS in Sect. 6.

\section{Dismantling the dichotomy}

As mentioned in Sect. 1, I cannot discern in the literature an explicit argument for the dichotomy between formal and historical analyses of science. Indeed, it would appear that the dichotomy - to the extent that it is explicitly acknowledged at all-is more typically perceived to exist (cf. the above quotations) than actually argued for. So why should it be the case, then, that formalism and history are essentially incompatible? In what follows, I reconstruct two possible arguments for the perceived dichotomy.

Before proceeding, though, it will prove useful to regiment our terminology. Let us mean by Integrated HPS any approach to doing both history of science in a way that successfully incorporates considerations from the philosophy of science, and philosophy of science in a way that successfully incorporates considerations from history of science. Let us refer to the former component as philosophical history of science and to the latter as historical philosophy of science. ${ }^{7}$ As the project of Integrated HPS has been pursued mainly by philosophers, it is perhaps not surprising to observe that the latter has received far more attention than the former. Accordingly, I will limit myself here to considering the 'historical philosophy of science' part of the Integrated HPS project. This serves to make the present discussion more tractable and is, in any case, not a severe restriction vis-à-vis the extant HPS literature. In light of this restriction in scope, the central question of this section becomes:

$\mathrm{Q}_{d}$ Why does there seem to be a dichotomy between formal philosophy of science and historical philosophy of science?

As our point of departure, let us first ask why there has been thought to be a dichotomy between history of science and philosophy of science in general. Fortunately, this dichotomy has been discussed much more explicitly by both philosophers and historians. The usual line of argument goes as follows: Traditionally, philosophers of science sought to make claims about science that were normative, general and abstract. By contrast, historians of science sought to make claims that were descriptive, particular and concrete. ${ }^{8}$ Prima facie, this presents us with two diametrically opposing ways to approach the study of science.

The question, then, becomes how an account that seeks to make normative, general and abstract claims about science can meaningfully draw on the descriptive, particular and concrete analyses of the historian. Here, the general strategy seems to be as follows. First, articulate a new philosophical method that seeks to be descriptive rather

\footnotetext{
7 Arabatzis (2017, p. 69) introduces a similar decomposition of the Integrated HPS project. Note that Arabatzis uses the initialism 'HPS' to refer to historical philosophy of science whereas I use it more generally to refer to the discipline of history and philosophy of science.

8 Pitt (2001, p. 373), Caneva (2012, p. 51), Cowan (1947, p. 11) and Dresow (2020, sec. 2) all stress the general/particular distinction. In addition, Burian (2002, pp. 398-399), Dresow (2020), Chang (2012) and Scholl and Räz (2016) allude to the abstract/concrete distinction, though only the latter two explicitly differentiate this distinction from the general/particular distinction. Lastly, see Giere (1973) for an influential discussion of the normative/descriptive distinction in the Integrated HPS literature.
} 
than normative. This automatically leads to a resolution of the normative/descriptive dichotomy. ${ }^{9}$ Next, present a separate line of argument for why the new, descriptive philosophy of science can overcome the general/particular and abstract/concrete dichotomies as well (the two dichotomies are not always sharply distinguished). In the case of the general/particular dichotomy, this involves (among other things) articulating criteria for how we can construct, select and interpret historical case studies without (philosophical) bias. In the case of the abstract/concrete dichotomy, this involves (among other things), articulating the way in which concrete historical episodes may help shape abstract philosophical concepts and vice versa. ${ }^{10}$

The descriptive methodology discussed most frequently in contemporary debates (i.e. from the 1990s onward) on Integrated HPS is that of naturalized philosophy of science, where the 'naturalism' consists in using historical case studies to confront our general/abstract philosophical theories with empirical 'data' to which they must conform. ${ }^{11,12}$ Whether historical case studies can indeed fill this role is a matter of ongoing debate. ${ }^{13}$

Now, what does all this mean for formal philosophy of science and its relation to historical philosophy of science? Well, let us first ask what the term 'historical philosophy of science' is now supposed to denote. In light of the preceding paragraph, 'historical philosophy of science' can now be taken to denote a particular, naturalistic approach to philosophy of science. The H/F dichotomy then becomes a methodological dichotomy; a dichotomy between formal methodology on the one hand, and a 'historical methodology' (e.g. naturalism) on the other. ${ }^{14}$ And indeed, on this construal of 'historical

\footnotetext{
9 This is only a rough characterization and glosses over the fact that our 'new' approach to philosophy of science need not be purely descriptive (see also footnote 12). The crucial point, here, is that there is typically perceived to be a problem with normative philosophy of science as traditionally understood, i.e. as involving a priori epistemic/methodological norms of scientific enquiry.

10 For more details on what these procedures involve, see the references provided in footnote 13. Particularly instructive here are Bolinska and Martin (2020) (general/particular) and Scholl and Räz (2016) (abstract/concrete).

11 'Naturalism' is a term with a long history and many uses in philosophy of science and analytic philosophy more broadly: cf. Price (2008), Kornblith (2016), Papineau (2021). Here, I use 'naturalism' in the vein of various post-positivist philosophers of science, e.g. Giere (1985), to denote an adherence to empirical methods (broadly construed) in the philosophy of science; see also Schickore (2011).

12 While naturalism is often assumed to imply non-normativity, it is not clear to what extent a naturalized philosophy of science is by definition non-normative. See Laudan (1990) for a prominent argument in favour of the notion that we can have a philosophy of science that is both normative and naturalized.

13 One of the earliest and most substantial attempts to ground philosophy of science in historical case studies was undertaken by Larry Laudan and his various collaborators at the Virginia Polytechnic Institute (VPI), resulting in Laudan et al. (1986) and Donovan et al. (1988). The VPI project (as it has become known) was eventually abandoned (Schickore 2018, p. 92). More recently, the debate has centred around resolving the 'dilemma of case studies' as posed by Pitt (2001). See Chang (2012), Scholl and Räz (2016) and Bolinska and Martin (2020)_and the references therein-for a representative cross section of this more recent debate. See Schickore (2011) for a prominent critique of the use of historical case studies in the philosophy of science.

14 Schickore (2011) has convincingly argued that the participants in the 'older debate' concerning Integrated HPS (circa 1960s and '70s) construed 'historical philosophy of science' rather differently, viz. not as a naturalistic but as a hermeneutic approach to philosophy of science. We need not concern ourselves here with this point of nuance, however, since both these construals still take 'historical philosophy of science' to denote some kind of methodological stance. And this, as we will see in a moment, is all we require to rebuke the $\mathrm{H} / \mathrm{F}$ dichotomy.
} 
philosophy of science', the H/F dichotomy gains some prima facie plausibility. After all, the ' $\mathrm{H}$ ' and the ' $\mathrm{F}$ ' now signify two different philosophical methodologies. And unless we are presented with an argument that would indicate otherwise, we have no reason to suppose two (seemingly very different) methodologies for the study of same subject matter to be compatible in any substantial sense.

Moreover, in the case of formal versus naturalistic approaches to philosophy of science, we have a specific reason to suppose that these two different methodologies will not mesh. Namely, we might look at the history of philosophy of science and, focusing in particular on the formal analyses found in logical empiricism, conclude that formal philosophy of science invariably relies on extra-scientific, a priori commitments about the nature of science. Of course, this stands in stark contrast with the naturalistic approach, the aim of which is to reject explicitly appeals to such $a$ priori commitments. ${ }^{15}$ In this sense, formal philosophy of science could be said to be anti-naturalistic. $^{16}$

These considerations lead to the first reconstructed argument for the H/F dichotomy:

Reconstructed Argument 1. Formal philosophy of science and historical philosophy of science rely on two opposing methodologies: the former is aprioristic, whereas the latter is naturalistic. Hence, formal and historical philosophy of science are intrinsically incompatible.

What are we to make of this argument for the H/F dichotomy? At this point, we might take up the question of how to bring together formal methodology with the naturalistic approach to philosophy of science outlined above. Incidentally, note that there are no particularly compelling grounds to deny that this can be done. ${ }^{17}$ There is, however, a much more straightforward way of overcoming Reconstructed Argument 1. For, while formal philosophy of science consists in the use of formal methods, we are by no means obliged to construe 'historical philosophy of science' as similarly denoting a particular methodological stance.

But if not as a methodological stance, then how are we to construe 'historical philosophy of science'? Here is an alternative. Simply take 'historical philosophy of science' to denote any philosophical account of science which engages substantially with the history of science as a subject matter. Let us call this the subject view of historical philosophy of science, to be contrasted with what we might retroactively call the methodological view of historical philosophy of science considered above. ${ }^{18}$

\footnotetext{
15 Scholl (2018, pp. 214-216) explicitly contrasts the 'a priori approach' used in traditional philosophy of science with the naturalistic approach that developed from the 1980 s onward. While Scholl mentions logical empiricism as an example of the a priori approach, he does not mention formal approaches in general. More explicitly, Tsou (2015) contrasts Carnap's 'logical analysis' with Kuhn's 'historical analysis', noting that the aprioristic approach of the former is incompatible with the naturalistic approach of the latter.

16 By this light, a methodology like Carnapian explication (cf. Carnap 1950/1962, pp. 1-18), which often goes hand in hand with the use of formal methods, may also be called anti-naturalistic.

17 Modern-day physics is arguably the paradigmatic example of how formal methods and naturalism may go hand in hand. For an interesting example of how one can combine formal methods with a naturalistic approach to the study of history, see the field of cliodynamics (Turchin 2003).

18 Of course, the methodological view will almost always come along with a focus on history of science as a subject matter. But, conversely, the subject view may, but need not, come along with a commitment
} 
To make matters more tangible, let me briefly expand on the ways in which the subject view manifests in practice. There are, of course, many different ways in which the history of science could conceivably enter into our philosophical reflections as a subject matter. But there are two particular varieties of the subject view that particularly deserve mention.

The first variety includes all those accounts that seek to elucidate the 'change', 'development', 'dynamics' or 'diachronics' of scientific knowledge. Topics such as 'theory choice' and 'incommensurability' frequently appear here as major themes. Examples abound: see e.g. Stegmüller (1976), Pearce and Rantala (1983a) and the various papers in Hintikka et al. (1981, sec. 1) and Soler et al. (2008). ${ }^{19}$ We may characterize this variety of historical philosophy of science as being concerned with the issue of scientific change.

The second variety of the subject view is somewhat less common. On this construal, historical philosophy of science consists in the study of past scientific theories, concepts and methods with the aim of informing one's conceptual analysis of metascientific concepts, e.g. the concepts of theory, explanation or confirmation. For an example of this kind of historical philosophy of science, applied to the concept of explanation, see Jansson (2014). Drawing inspiration from Dutilh Novaes (2020), we might call this variety of historical philosophy of science genealogical analysis. ${ }^{20}$

In sum, then, we find ourselves with at least three distinct views on historical philosophy of science: one view which I have dubbed the methodological view and two varieties of what I have called the subject view. In the end, this yields the following three ways of construing historical philosophy of science:

MTD Historical philosophy of science as a (naturalistic) methodology.

CHN Historical philosophy of science as a focus on scientific change.

GEN Historical philosophy of science as genealogical analysis. ${ }^{21}$

As mentioned in Sect. 1, different ways of construing historical philosophy of science will naturally lead to different ways of construing Integrated HFS as well (since the latter consists in the synthesis of formal philosophy of science and historical philosophy of science). This observation, as we will see momentarily, is crucial.

\section{Footnote 18 continued}

to a particular (naturalistic) methodology. Indeed, this is the crux of my rebuttal of Reconstructed Argument 1 (see below).

19 More on these first two examples in Sects. 3 and 4.

20 Dutilh Novaes uses the term 'genealogy' to refer to the specific genealogical method found in the work of Foucault, and considers the ways in which it might interface with a specific kind of conceptual analysisviz. Carnapian explication (see footnote 16). By contrast, my use of the term 'genealogical analysis' is much more liberal, referring to any kind of conceptual analysis which relies substantially on historical considerations.

21 As noted in footnote 5, Schickore (2018) distinguishes five different types of historical philosophy of science; a typology she attributes to Laudan (1981). Her five-fold typology maps onto my three-fold classification as follows. My CHN corresponds to Schickore's (1). Her (2) corresponds roughly to my GEN, though the exact extent to which we may identify the two is somewhat unclear. What I have called the 'methodological view' (MTD) corresponds to her (3). Finally, Schickore's (4) and (5) fall outside the scope of my classification, since they do not qualify as 'historical philosophy of science' in my sense (being, rather, different activities involving both history and philosophy). 
Let us now return to our appraisal of Reconstructed Argument 1, and consider how it fares in light of the above distinctions. As noted above, the argument is prima facie plausible (though still far from obvious) on the methodological view. However, on the subject view of historical philosophy of science (be it in sense CHN or GEN), the argument loses its force. We are, after all, free to use whatever method we like for the study of a certain subject matter, provided that the chosen method helps us achieve the goals we have set for our particular enquiry. Hence, even if we take Reconstructed Argument 1 to be a sound argument against Integrated HFS on the methodological view of historical philosophy of science, the argument becomes powerless once we adopt the subject view.

At this point, however, another objection to Integrated HFS might emerge. More specifically, one might concede the subject view of historical philosophy of science, but may object that, as a subject matter, history is 'just too complex' to permit any kind of worthwhile formal analysis. Another, more specific version of this kind of objection is the charge that history is too variable or chaotic for us to discern any invariant formal structures. ${ }^{22}$ This leads us to:

Reconstructed Argument 2. History, as a subject matter, is not susceptible to formal analysis, since it is too complex/variable/chaotic. Hence, formal philosophy of science and historical philosophy of science are intrinsically incompatible.

Reconstructed Argument 2 has little to recommend itself. First, consider the generic version of the argument, which cites the 'complexity' of history. To be sure, history is complex. But this observation, by itself, does not at all establish that history resists formal analysis. Indeed, the point of formalization is exactly to take something complicated and cast it into a more tractable form. This version of the argument can thus be dismissed out of hand. ${ }^{23}$ Next, consider the more specific version, which cites the 'variable' or 'chaotic' nature of history. An initial response might be that the formal philosopher is by no means obliged to seek out invariant formal structures. Indeed, the aim of formal analysis might just as well be to elucidate the change in the formal structure of, say, scientific theories throughout history. In addition, and more importantly, note that the presupposition that science has no temporally invariant features is an exceedingly strong one, and it is hard to see on what basis it could be justified. ${ }^{24}$

I conclude that there is no principled argument against Integrated HFS, as long as we are content to construe 'historical philosophy of science' according to the subject

\footnotetext{
22 Both Pitt (2001, p. 381) and Kuukkanen (2016) note that the intrinsic variability of history poses a challenge to integrating history and philosophy of science, though neither explicitly refers to formal philosophy of science. Importantly, Kuukkanen merely attributes such a view of history to historians (and sociologists) of science, without explicitly endorsing this view himself.

23 This is not to say that providing a formal analysis of history (of science) is straightforward. Indeed, exactly how much of history's complexity we can abstract away before we end up with a caricature beyond recognition is itself a complicated question that will have to be taken up on a case-by-case basis. Importantly, however, this difficulty is by no means unique to history as a subject matter. Rather, it is a difficulty that must be confronted by the application of formal methods to any subject matter for which such methods have not yet proved their worth. I thank an anonymous reviewer for pushing me on this point.

24 I agree with Bolinska and Martin when they write: "[W]e should be suspicious of any account of history that suggests that it is either always inherently stable or always inherently chaotic. One of the tasks of historical inquiry, then, is to offer arguments for why we should regard a particular system as either robust or chaotic, to what extent, and with respect to what" (Bolinska and Martin 2020, p. 43).
} 
view. This last qualification is of course not a trivial one, especially once we consider the prominence of methodology debates in the post-positivist discourse on historical philosophy of science. But whatever one's views on the naturalness of the methodological view may be, it is clear that the subject view is a natural construal in its own right; and it is this construal that I will assume for the remainder of the paper. It is, of course, entirely possible that - even if we cannot (currently) articulate a principled argument against Integrated HFS - it is still a practical matter of fact that formal accounts of science have proved hopelessly a-historical. An excursion into post-positivist formal philosophy of science, however, shows this practical objection to be just as ill-founded as the two principled objections considered above.

\section{Formalized macro-units}

While philosophy of science as a whole underwent a sharp historical turn in the second half of the twentieth century, that same period of time saw another major development internal to formal philosophy of science. This was the emergence of the structuralist approach to formal philosophy of science, which would come to displace the sentential approach favoured by the logical empiricists. Of particular interest here is the movement of Munich structuralism, widely known as the most rigorous and well-developed school of formal philosophy of science. ${ }^{25}$ In addition, the rise of Munich structuralism prompted the development of another, closely related (though lesser-known) version of the structuralist approach, viz. the abstract logic approach developed by David Pearce and Veikko Rantala.

Much could, and has been, said about the programme of Munich structuralism and, to a lesser extent, that of the abstract logic approach. Significant for our current discussion is the fact that, with the rise of Munich structuralism, formal philosophers of science began to display a much stronger interest in the historical dimension of science than they ever had during the era of logical empiricism. Particularly noteworthy are: (I) the initial efforts of the Munich structuralists to formalize Thomas Kuhn's notion of paradigm (Kuhn 1962) and its attendant account of scientific change, and (II) the subsequent efforts by Rantala and, especially, Pearce to formalize Larry Laudan's notion of research tradition (Laudan 1977) and its attendant account of scientific change. Together, (I) and (II) constitute a little-known strand of formal philosophy of science, which I refer to here as the study of formalized macro-units (FMU). ${ }^{26}$

The mere existence of FMU should already be enough to cast doubt on the the tenability of the 'practical' objection mentioned at the end of the previous section. Indeed, I will argue in Sect. 4 that FMU is an example of formal philosophers of science engaging with history of science in exactly the way that mattered-or, at least,

\footnotetext{
25 While the label 'structuralist approach' strictly speaking refers to a wider family of approaches than just Munich structuralism, I will here use the adjective 'structuralist' only in connection with Munich structuralism.

26 Here, I use 'macro-unit' as an umbrella term for concepts as paradigm, research programme, research tradition, conceptual framework, thema, style of reasoning, and the like. In other words: a 'macro-unit' is a unit of analysis that stands above and guides the formation and/or development of individual scientific theories.
} 
in a way that should have mattered to contemporaneous historical philosophers of science. ${ }^{27}$ But before turning to that argument, let me make a few more expository remarks about what FMU, as exemplified in the programmes of Munich structuralism and the abstract logic approach, consists in.

\subsection{History and Munich structuralism}

Munich structuralism originates in the work of American philosopher Joseph D. Sneed (1971) and was subsequently taken up by Munich-based philosopher Wolfgang Stegmüller, who saw in the structuralist formalism the key to the clarification of Kuhn's account of scientific change. Accordingly, in his (1976), Stegmüller presents us with what we may take to be one of the first substantial attempts at Integrated HFS. ${ }^{28}$ Kuhn himself, moreover, offered a tentative endorsement of this use of formal methods:

Contrary to a popular impression, I am not an enemy of formalism. (Could anyone trained as a theoretical physicist really take such a position?) Rather, I've objected to the sort of formalism long applied to philosophy of science, and I've had no notion how to find a substitute for it...Letter from Kuhn to Stegmüller, 14 August 1974, as quoted in Damböck (2014, p. 69).

Stegmüller, approaching my work through Sneed's, has understood it better than any other philosopher who has made more than passing reference to it... Whatever its limitations (I take them to be severe), formal representation provides a primary technique for exploring and clarifying ideas (Kuhn 1976).

In addition to Stegmüller's substantial interest in combining Sneed's formalism with Kuhn's view of scientific change, subsequent structuralist philosophers maintained an interest in formalizing the historical dimension of science, as evidenced by the inclusion of a chapter on the 'diachronic structure of theories' in Balzer et al. (1987).

The central concept in the structuralist account is that of a scientific theory. Indeed, it is from its analysis of theories that the structuralist account derives its name. In short, structuralists formalize a scientific theory $T$ in terms of classes of mathematical structures. (I shall henceforth omit the adjective 'mathematical', whenever it is convenient to do so.) Here, a structure is a tuple of the form

$$
\mathfrak{S}=\left(D_{1}, \ldots, D_{n_{0}}, R_{1}, \ldots, R_{n_{1}}, f_{1}, \ldots, f_{n_{2}}, c_{1}, \ldots c_{n_{3}}\right)
$$

where each $D_{i_{0}}$ is some domain and the $R_{i_{1}}, f_{i_{2}}$ and $c_{i_{3}}$ denote some relations, functions and constants defined over the various domains. Moreover, a class of structures is typically specified by a list of particular set-theoretic properties, also called a settheoretic predicate $\tau$. Such a class of structures may then be written as:

$$
C=\{\mathfrak{S} \mid \tau(\mathfrak{S})\}
$$

\footnotetext{
27 More on this latter qualification in Sect. 4.

28 Cf. Stegmüller (1973) for the original, German-language monograph.
} 
where each $\mathfrak{S}$ is a structure in the sense of (1) and $\tau($.$) denotes a set-theoretic predicate.$

In the structuralist account, the formal representation $F T$ of (our intuitive conception of) a scientific theory $T$ consists of two main components: a theory-core $K$ and a class of intended applications $I$. Symbolically: $F T=(K, I)$. Presenting the full definitions of these components, while straightforward, would be a needlessly lengthy exercise. For present purposes, a cursory presentation will suffice. ${ }^{29}$

First, the theory-core $K$ consists of several classes of structures defined relative to a single set-theoretic predicate $\tau$. Intuitively, $\tau$ may be thought of as an axiomatization of $T$ in mathematical English. ${ }^{30}$ More specifically, we define a theory-core as a tuple $K=\left(\mathbf{M}_{p}, \mathbf{M}, \mathbf{M}_{p p}\right)$, with the class $\mathbf{M}_{p}$ of potential models of $T$, the class $\mathbf{M}$ of (actual) models of $T$ and the class $\mathbf{M}_{p p}$ of partial potential models of $T .^{31}$

Second, regarding the class $I$ of intended applications, the structuralists note that "that intended applications of a theory cannot be characterized by purely formal means" (Balzer et al. 1987, p. 87), italics removed. However, to the extent that the class $I$ can be formally specified, the structuralists state the following: the class $I$ of intended applications is a subclass of the class $\mathbf{M}_{p p}$ of partial potential models. That is: $I \subseteq \mathbf{M}_{p p}$.

Now, the formalization of the Kuhnian paradigm-concept and the attendant theory of scientific change can be summarized in three points (A-C), which I take up in turn.

(A) The formal representation $F T$ of $T$ is modified slightly so as to accommodate several aspects of the historical context in which $T$ is situated. More specifically, we now have a diachronic theory-element $F T=(K, I, S C, h)$ where $K$ and $I$ are as before and $S C$ and $h$ are a scientific community and a historical period respectively such that $S C$ intends to apply $K$ to $I$ over the course of $h$.

Note that neither the notion of a scientific community nor that of historical period is specified formally. Nor, for that matter, is it spelled out what it means for a scientific community to intend to apply. Rather, these notions are all introduced into the structuralist account as 'pragmatic primitive concepts' (ibid., p. 211).

Before proceeding, we require two preliminary notions. First, there is the notion of one diachronic theory-element $F T^{\prime}$ being a specialization of another diachronic theory-element $F T$. Roughly, we say that $F T^{\prime}$ is a specialization of $F T$ if the following conditions hold:

$\mathrm{SP} 1 \mathbf{M}_{p}=\mathbf{M}_{p}^{\prime}, \mathbf{M}_{p p}=\mathbf{M}_{p p}^{\prime}$ and $\mathbf{M}^{\prime} \subseteq \mathbf{M}$,

$\mathrm{SP} 2 \quad I \cap I^{\prime} \neq \varnothing$,

SP3 $h$ historically precedes $h^{\prime}$ and $S C=S C^{\prime}$.

Second, we have the notion of a theory-net. Roughly, a theory-net is a pair $N=$ $(|N|, \sigma)$ where $|N|$ is a class of diachronic theory-elements and $\sigma \subseteq|N| \times|N|$ is a binary relation such that $F T^{\prime} \sigma F T$ iff $F T^{\prime}$ is a specialization of $F T$.

\footnotetext{
29 See Balzer et al. (1987, ch. 1-2) for a more detailed presentation.

30 This is what Stegmüller (1976, p. 35) refers to as "informal axiomatization by definition of a set-theoretic predicate" and should be distinguished from the formal notion of axiomatization found in logic. For a prototypical example of the former kind of axiomatization, consider how the properties of associativity, identity and invertibility — expressed in mathematical English—are called the 'axioms' of the structure known as a group.

31 For brevity's sake, I omit the global constraint GC and general link GL from the definition of theorycore.
} 
Building on these definitions, we can now characterise the structuralists' formalization of scientific change:

(B) The development of a scientific theory throughout history is represented formally as a theory-evolution. Roughly, a theory-evolution is a finite sequence $E=\left(N_{1}, N_{2}, \ldots N_{k}\right)$ of theory-nets such that for every $F T^{\prime} \in\left|N_{i+1}\right|$ there is a $F T \in\left|N_{i}\right|$ such that $F T^{\prime}$ is a specialization of $F T$.

Lastly, while the notion of a diachronic theory-element already incorporates some aspects of a theory's historical context—viz. scientific community and historical period-we might also be interested in how other, more substantial contextual factors influence a theory's development. Here, the influence of Kuhnian philosophy of science shines through:

(C) Let $E=\left(N_{1}, N_{2}, \ldots, N_{k}\right)$ be a theory-evolution. A theory-element $\left(K_{0}, I_{0}\right)$ is said to be a Kuhnian paradigm for $E$ if for any theory-net $N_{i}$ in $E$ and any diachronic theory-element $F T=(K, I, S C, h)$ in $\left|N_{i}\right|$ we have: (i) $K_{0}$ is a core specialization of $K$ and (ii) $I_{0}$ is acknowledged as a paradigm class for $I$ by $S C$ over the course of $h$.

Here, the notion of a core specialization is simply the notion of a specialization restricted to theory-cores. On the other hand, what it means for a class $I_{0}$ to be acknowledged as a paradigm class is left unanalysed. Again, we have here an example of a pragmatic concept (in the sense that it pertains to the relation between theories and the users of those theories) that is treated as a primitive concept within the structuralist framework. ${ }^{32}$

Of course, we may wonder if and how this seemingly highly abstract framework can be applied to actual history of science. Finally, then, it is worth pointing out that the structuralists' diachronic account of science is not only an exercise in abstraction, with Balzer et al.(1987, p. 223ff) applying the framework to two concrete episodes of scientific change: the development of classical particle mechanics from Newton to Laplace and the development of simple equilibrium thermodynamics from the 1870 s to the 1930s. Hence, while we can criticize the structuralists' diachronic account of science on several historical-methodological grounds, a failure to engage with concrete episodes of scientific change should not be one of them. ${ }^{33}$

\footnotetext{
32 Although Balzer, Moulines and Sneed do not explicitly connect their notion of Kuhnian paradigm to (one of the various) notions of paradigm articulated by Kuhn himself, it seems we can intuitively think of the theory-core $K_{0}$ and paradigm class $I_{0}$ as the 'symbolic generalizations' and 'exemplars' respectively of the normal scientific tradition represented by E; cf. Kuhn's 1969 postscript to Structure (Kuhn 1962) for a more detailed discussion of these concepts.

33 But what is accomplished by reconstructing such concrete episodes in terms of the structuralist framework? While a global aim of the structuralists was the formalization and precisification of crucial historical-philosophical concepts such as paradigm and normal scientific change (more on which in Sect. 4), it is indeed not clear what kind of specific insight the formal analysis of such concrete historical case studies is supposed to provide. On this point, Balzer, Moulines and Sneed have little to say. Indeed, the only (philosophical) insight they draw from their case studies is that Kuhn's notion of paradigmatic application might be in need of revising (ibid., p. 233). On the whole, however, Balzer, Moulines and Sneed seem to take the formal reconstruction of the historical development of certain theories and/or paradigms as a goal in its own right. Similar comments apply, grosso modo, to the abstract logic approach discussed in Sect. 3.2. I thank an anonymous reviewer for pushing me on this point.
} 


\subsection{History in the abstract logic approach}

The earliest expression of the abstract logic approach that I am aware of is given by Rantala (1978), who starts off the research programme by remarking that "[J.D. Sneed's approach to the philosophy of science] has compelled philosophers to reconsider what are the most appropriate logical tools in the study on the structure and dynamics of empirical theories" (ibid., p. 233). Subsequently, we are introduced to the idea that the use of abstract logic, also known as abstract model theory (cf. Barwise and Feferman 1985), may lead to a methodological enrichment of the scientific theories debate; in particular, it may allow us to extend and improve upon various aspects of Munich structuralism. ${ }^{34}$ These reflections would eventually culminate in a closely related, but distinct programme of formal philosophy of science (Pearce and Rantala 1983b), sometimes referred to as the abstract logic approach.

In addition to reacting against Munich structuralism in general, Pearce and Rantala also reacted against the structuralists' diachronic analysis of science in particular. An important aim of Stegmüller (1976) was to show that pairs of scientific theories deemed incommensurable by the Kuhnian are nevertheless connected by a relation of reduction, and hence amenable to 'rational comparison', provided that we construe the notions of theory and reduction in a structuralist vein. The idea that the structuralist approach is in some sense privileged when it comes to the formalization of scientific change has been criticized extensively by Pearce $(1982,1986)$. At the heart of Pearce's rejoinder is his rebuke of Stegmüller's implicit presupposition that reducibility does not imply translatability, and hence commensurability.

Parallel to these negative arguments, Rantala and, in particular, Pearce have articulated a positive proposal for a formal model of scientific change, the locus of which may be found in Pearce and Rantala (1983a, 1984). This formal model is developed most extensively in Pearce's (1987) monograph, where - in addition to reprising his previously mentioned criticism of Stegmüller-he undertakes an extensive appraisal, revision and formalization of (select aspects of) Laudan's (1977) problem-solving model of scientific progress. ${ }^{35} \mathrm{~A}$ key concept here is the notion of the theory-ensemble, which serves as Pearce and Rantala's formal counterpart of Laudan's notion of research tradition. Let us, accordingly, refer to this component of the abstract logic approach as the ensemble model.

It is important to distinguish three different levels of generality at which the ensemble model operates. At its most general, the ensemble model is a template for the formal representation of theories of scientific change in terms of collections of scientific theories and relations between them. The ensemble model, in this sense, comes without any specific commitments regarding the nature of scientific theories, interthe-

\footnotetext{
34 Two specific examples where Rantala takes abstract model theory to come in useful are: (I) the definition of the concept of logical matrix and (II) the definition of the concept of Ramsey eliminability, as originally found in Sneed's 1971 monograph. See also Rantala (1980) and Pearce (1981) for more detailed appraisals of structuralist philosophy of science and the potential applications of abstract model theory.

35 More precisely, Pearce tells us that his aim is "not so much to present a formalization of Laudan's theory, but rather to show how certain types of continuity or discontinuity in scientific change can be given a fairly precise description... [t]o this end, we shall make make use of some core features of Laudan's model of growth, but at the same time try to fill in some of the gaps and correct some of the inadequacies of that account..." (1987, p. 123).
} 
ory relations or the process of scientific change itself. At its intermediate level of generality, the ensemble model comes with specific commitments about the nature of scientific theories and intertheory relations, viz. that these are best in understood in the sense of the abstract logic approach, while still remaining neutral with regard to the process of scientific change. Lastly, at its most specific, the ensemble model has been used to formulate a specific theory of scientific change, viz. a modified version of Laudan's problem-solving model of scientific progress.

At the heart of the ensemble model (regardless of the level of generality at which we consider it) is the eponymous concept of theory-ensemble. It is this concept that serves as the 'macro-unit' in terms of which Pearce and Rantala aim to analyse scientific change. Its definition is easily stated: A theory-ensemble is a tuple $E=\left(|E|, \alpha_{1}, \ldots, \alpha_{n}\right)$, where $|E|$ is a finite set of scientific theories and the $\alpha_{1}, \ldots, \alpha_{n}$ are binary relations on $|E|$. More specifically, each $\alpha_{i}$ represents a particular kind of reduction relation between the theories in $|E| .{ }^{36}$

As mentioned, the notion of theory-ensemble serves as the formal counterpart to Laudan's informal notion of a research tradition. ${ }^{37}$ More precisely, a theory-ensemble represents, not the entire research tradition, but rather a particular stage of its development. In this sense, the individual theory-ensemble is a 'static' entity. ${ }^{38}$ In turn, the evolution of a research tradition through history is construed as a sequence of theory-ensembles, in which each member of the sequence is related to its immediate predecessor/successor in such a way that it reflects the continuity of the research tradition as a whole. ${ }^{39}$

Much more could be said about the ensemble model of scientific change. Of particular interest is the question how, if at all, theory-ensembles as defined above can articulate the ontological, epistemic and methodological commitments that Laudan's notion of research tradition is supposed to codify. At this point, we could investigate at length the various homogeneity requirements that Pearce and Rantala impose on the sets of theories that make up theory-ensembles (cf. Pearce and Rantala 1983a, pp. 352354). We will not need to do so for present purposes, however. Instead let us, drawing on our discussion of Munich structuralism as well as the abstract logic approach, return to consider the practical objection against Integrated HFS, as introduced near the end of Sect. 2, and see where we stand.

\footnotetext{
36 This definition does not presuppose that we explicate scientific theories or intertheory relations in line with the abstract logic approach (cf. the above disclaimer about the three different 'levels of generality' at which the ensemble model operates). Of course, it should not come as a surprise that in practice, Pearce and Rantala often combine the ensemble with their other accounts of theories and intertheory relations.

37 Pearce and Rantala seem to use the term 'research tradition' in two distinct ways: (I) to refer to research traditions in Laudan's sense, e.g. in Pearce (1987), and (II) as a more generic term for any kind of historical macro-unit: see e.g. their (1983a, 1984). For this exposition, however, this ambiguity is unimportant.

38 Additional qualification: Pearce (1987, p. 132) notes that a theory-ensemble will not contain "the entire set of theories asserted within [a research tradition] at the stage in question, but only a central 'core' of theories...".

39 For a more detailed presentation of the ensemble model, including the way in which theory-ensembles may be used to encode salient aspects of a research tradition's historical context, I refer the reader to Pearce (1987, ch. 5).
} 


\section{On usefulness}

In the previous section, we have seen how formal philosophers have made sustained and substantial efforts to engage with historical philosophy of science. Nevertheless, one might object that these efforts, however noble, still miserably miss the mark. More specifically, it might be objected that neither of the previously discussed frameworks engages with history in a way that would be satisfying to historical philosophers of science-or, for that matter, to actual historians of science. On this point, our hypothetical opponent might very well be in the right. However, I contend thatat least by the lights of contemporaneous historical philosophers of science-FMU should be considered to have made a useful contribution to historical-philosophical discourse. I will argue for this point in a two-pronged fashion: first, I will identify some of the criticisms that were levelled against prominent historical-philosophical accounts of science by other historical philosophers of science (Sect. 4.1). Having done so, I will show that FMU provided useful tools for addressing these criticisms (Sect. 4.2).

\subsection{Vagueness in historical philosophy of science}

It would scarcely be an exaggeration to say that "[t]he discussion between Kuhn and his critics was often hampered by ambiguity and confusion" (Kockelmans 1979, p. 188). Indeed, we find in the literature five different notions of 'incommensurability' (Marcum 2015), twenty-one(!) different readings of 'paradigm' (Masterman 1970) and seven different versions of the person 'Kuhn' himself (Kuukkanen 2009). Unsurprisingly, the vagueness of its central concepts provided a direct source criticism of Kuhn's (1962) account of scientific change. Shapere (1964), in a review of The Structure of Scientific Revolutions, bemoans at length the lack of clarity with which Kuhn articulates the notion of paradigm, observing that "anything that allows science to accomplish anything can be a part of (or somehow involved in) a paradigm" and subsequently concluding that " the explanatory value of the notion of a paradigm is suspect” (ibid., p. 385). Similarly, Gaukroger (1978) rejects Kuhn's paradigm-concept as inadequate, noting that Kuhn fails to pin down the notion with enough precision for us to determine when two scientists are working in different or identical paradigms. ${ }^{40}$

Vagueness of concepts can also be seen to underpin-albeit more implicitlyseveral other charges that have been brought against Kuhn's account. Consider, for instance, the charge that Kuhn makes a dogmatist out of the 'normal scientist'.

The charge of dogmatism was famously levelled by Popper (1970), who remarked that "the 'normal' scientist, as Kuhn describes him, is a person one ought to be sorry for" (ibid., p. 52). For Popper, of course, it is the testability of theories, rather than Kuhn's notion of puzzle solving, that is characteristic of scientific enquiry. Kuhn, in turn, rejects Popper's testability criterion, noting that "[o]n some occasions, at least, tests are not requisite to the revolutions through which science advances" (Kuhn 1970,

\footnotetext{
40 Larmore (1981, p. 319) amusingly paraphrases Gaukroger's critique as "the obvious complaint that [Kuhn's idea of paradigms] is too amorphous to be of any analytic use".
} 
p. 10) $)^{41}$ but that, in line with his own outlook, "none of these was replaced before it had ceased adequately to support a puzzle-solving tradition" (ibid.). Here, however, conceptual vagueness rears its head once more. Responding to Kuhn's paper in the same volume, Watkins (1970) — a convinced Popperian-retorts that Kuhn's notion of adequate support "is essentially vague; for since Kuhn insists that there are always anomalies and unsolved puzzles, the difference between supporting, and failing to support, a puzzle-solving tradition is merely one of degree..." (ibid.), original italics. It is not my intent here to appraise Watkins' rejoinder. Rather, it is simply to show how vagueness of concepts has contributed (for better or worse) to perpetuating an otherwise substantive philosophical dispute.

The point made here about Kuhn applies to post-positivist historical philosophy of science more generally. Lakatos (1970) prominently suggests the methodology of scientific research programmes (MSRP) as a combination of Popperian rationalism and Kuhnian historical sensitivity. However, Lakatos, just as Kuhn, has been charged with failing to clarify his central concepts. Indeed, Thomason (1992, p. 193) and, again, Gaukroger (1978) have noted that Lakatos has failed to specify clear criteria of individuation for research programmes, with Thomason in particular arguing that this vagueness (among other factors) undermines the MRSP account of the Copernican revolution (cf. Lakatos and Zahar 1976). Relatedly, Lakatos' concept of novel prediction has been charged with being overly vague (Gonzalez 2001); a vagueness that, in turn, threatens to obfuscate the core of Lakatos' account. As noted by Carrier (1988, p. 206): “Most of the key MSRP notions such as 'progressive' or 'degenerating programmes' remain vague unless we can determine what constitutes confirming evidence".

Laudan (1977), following in the wake of Kuhn and Lakatos, promotes a conception of scientific rationality as consisting in the appraisal of the problem-solving effectiveness of rival research traditions. While Giere (1978) praised the account for its clarity, others lamented the vagueness of its central concepts. In the same vein as Gaukroger's concerns regarding the paradigm-concept, McMullin (1979, p. 627) wonders how research traditions are to be individuated. Jardine (1978), in a particularly unfavourable review, notes that Laudan's research traditions are "so vaguely defined as to cover almost any imaginable conglomeration of theories" (ibid., p. 416). A related and oft-cited source of criticism, e.g. by Musgrave (1979), Baigrie and Hattiangadi (1981) and the two previously mentioned authors, is that Laudan fails to specify with enough clarity his envisaged measure of problem-solving effectiveness, making his account of scientific rationality effectively unworkable.

\subsection{Formalized macro-units: redux}

We see that vagueness of central concepts is a recurring source of criticism in appraisals of post-positivist historical philosophy of science, with the lack of clear criteria for individuating the various historical macro-units (paradigm, research programme, research tradition, etc.) being a particularly striking commonality. Indeed, Matheson and Dallmann (2017, sec. 4), in presenting general criticisms of "historicist theories of scientific

\footnotetext{
41 Kuhn cites Ptolemaic astronomy as an example (ibid.).
} 
rationality", explicitly address this "problem of implementation" and conclude that "[m]ore needs to be said about the standards for individuating large-scale theoretical units if the general claims about the nature of science and scientific methodology are to be evaluated" (ibid.).

As a result, it seems reasonable to suppose that sustained efforts at clarifying the nature of these macro-units should-by the lights of post-positivist historical philosophers of science-be welcomed as a valuable addition to their discourse. This is, of course, exactly what the frameworks making up FMU aim to do, with Stegmüller (1976) and Balzer et al. (1987, ch. 5) precisifying the concept of paradigm ${ }^{42}$ and Pearce and Rantala (1983a) and Pearce (1987) precisifying the concept of research tradition. Already, then, we see that FMU is perfectly poised to fill a lacuna that was identified by historical philosophers of science themselves.

There are, however, even more compelling arguments for the 'usefulness' of FMU. First, consider the case of Kuhn. As is well-known, Kuhn's doctrines surrounding incommensurability led to major controversies between rationalists, Kuhnians and social constructivists. Any suggestion for how to wed incommensurability through revolutionary episodes of scientific change with a rationalist picture of theory-choice would thus have to be considered, at the time, to be a highly salient contribution to historical philosophy of science. And this, as it turns out, was exactly one of the major aims of Stegmüller (1976), ${ }^{43}$ who claimed that the formal instrumentarium of the structuralist approach provided all the necessary tools to combine Kuhn's account of scientific change with a rationalist picture of theory-choice. It seems clear, then, that whatever benchmarks of usefulness one would like to employ, the structuralists' diachronic account of science can be considered 'useful' to the contemporaneous historical philosopher of science. ${ }^{44}$

Similarly, we see that Pearce and Rantala's ensemble model, as discussed in Sect. 3.2, provided substantive answers to some of the main criticisms that were levelled against Laudan's account of scientific change; criticisms that, so we have seen, were levelled by historians and historical philosophers of science themselves. Not only does Pearce (1987, ch. 5) provide the asked-for clarification of the concept of research tradition, he also provides in-depth assessments and clarifications of several key concepts needed for Laudan's account, such as those of problem-sharing and problem-solving effectiveness. Again, it seems clear that whatever benchmarks of usefulness one would like to employ, Pearce and Rantala's ensemble model may be said to meet them.

I conclude that efforts to invalidate FMU as an example of 'useful' engagement with historical philosophy of science ultimately fall flat. Of course, none of this is meant to say that historical philosophers of science should have uncritically endorsed the solutions provided by Pearce, Rantala and the Munich structuralists. The above is only meant to show that these efforts are worthy of acknowledgement, not endorsement.

\footnotetext{
42 In fact, the structuralists also expounded a formalization of Lakatos' concept of research programme. I will not, however, explore the details of this proposal here.

43 In the later work by Balzer et al. (1987), the focus on revolutionary change was dropped in favour of the formalization of episodes of normal scientific change (cf. Sect. 3.1).

44 By extension, the same can be said about Pearce's rebuttals of Stegmüller's position (cf. Pearce 1987, ch. 1-2).
} 


\section{The elusive role of 'practice'}

The overt interest from formal philosophers of science in historical philosophy of science, and Kuhn's endorsement of their efforts (cf. Sect. 3.1), make the prevalence of the $\mathrm{H} / \mathrm{F}$ dichotomy all the more striking. Even more striking is the fact that these efforts have-to my knowledge-received virtually no mention in any of the contemporary Integrated HPS literature. ${ }^{45}$ The sole exception here is Damböck (2014), who explicitly discusses the interaction between Munich structuralism and historical philosophy of science over the course of the 1970s and '80s; Damböck himself, however, is not explicitly concerned with the notion of Integrated HPS.

What might account for this lack of attention? In the absence of any negative appraisals of FMU in the Integrated HPS literature, a simple, but plausible conjecture is that the majority of scholars interested in Integrated HPS are simply unaware of its existence; a lack of awareness that is undoubtedly exacerbated by the unspoken preconception, discussed at length in Sect. 2, that formal methods cannot possibly cohere with historical philosophy of science.

A similar diagnosis is offered by Damböck, writing about the lack of interest from the 'Kuhn-Feyerabend community' in the structuralists' diachronic account of science: ${ }^{46}$

[I]n the absence of any real knockdown argument or substantive refutation of a given formal approach, a common reaction is to characterize that approach in very general terms as an irrelevant or unnecessary formalization or overformalization. However, this sort of argumentative strategy is not generally formulated explicitly...(ibid., p. 73), original italics.

Damböck, in particular, points towards the "sociological phenomenon of methodological purification (occurring on both sides), which led to a situation in which the methods of the respective other side were no longer available as reasonable philosophical methods" (ibid.).

Now, echoing Damböck, we are led to the thesis that the lack of interaction between the tradition of FMU — and formal philosophy of science more generally — and the modern community of Integrated HPS scholars is more naturally attributed to sociological factors, e.g. differing backgrounds and research interests of historical and formal philosophers of science, than to substantive arguments against the use of formal methods itself. ${ }^{47}$ More specifically, I believe we can understand the divide separating formal and historical philosophers of science by focusing on the importance of scien-

\footnotetext{
45 For example, see Laudan (1989), Nickles (1995), Schickore (2011), Miller (2012), Friedman (2008) and Dresow (2020): all are partly or wholly concerned with surveying the history of Integrated HPS, but none contain any reference to the tradition of formalized macro-units.

46 Damböck notes that the Kuhn-Feyerabend community most likely was aware of structuralist theorydiachronics — on account of the prominence of Kuhn's (1976) in the Kuhn literature-but choose to ignore it (ibid., pp. 72-73). I doubt, however, that the same can be said of the contemporary Integrated HPS community: unawareness, rather than 'positive ignorance' (to use Damböck's terminology) seems to me the most likely diagnosis.

47 From this point onward, I am no longer channelling Damböck.
} 
tific practice for both research communities. Let me, for the remainder of this section, attempt to substantiate this thesis.

The dealings of formal philosophers with 'practice' (broadly construed) go back a long way - to the work of the logical empiricists. As is well-known, Carnap (1939), drawing on Morris (1938), distinguished between the syntactic, semantic and pragmatic aspects of (scientific) languages. The first two, i.e. syntax and semantics, were subsumed by Carnap under his logic of science. On the other hand, there was the pragmatics of science, i.e. the study of all aspects relating to the users of scientific language, of which reflections on 'scientific practice' are a part. Of note is the fact that the pragmatics of science, as construed by Neurath, Frank as well as Carnap himself, was to proceed — not by means of logical analysis — but by the naturalistic-empirical methods of history, sociology and psychology.

The role played by pragmatics in logical empiricism and, in particular, Carnap's philosophy is an intricate one, as expertly described by Uebel (2013). What matters, for present purposes, is the observation that, already with Carnap, formal methodology was (crudely put) restricted to the analysis of syntax and semantics, whereas pragmatics was taken to necessitate a different, empirical methodology. ${ }^{48}$ And here, we find the harbinger of a tendency that would be shared by formal philosophers henceforth: a reluctance to analyse pragmatic concepts, including concepts relevant for describing scientific practice, in formal terms.

This reluctance is exemplified clearly in the framework of Munich structuralism. The structuralists have freely admitted that some of the fundamental concepts of the their framework, e.g. the notion of the intended applications of a theory, are only partially formalizable (cf. the quotation given in Sect. 3.1). In addition, the recalcitrance of pragmatic concepts to formalization shines through especially in their diachronic account of science. As noted in Sect. 3.1, the structuralists' definition of diachronic theory-elements requires the introduction of several 'pragmatic primitive concepts' - indeed, it is exactly because these concepts are 'pragmatic', that they are left 'primitive'.

At the same time, however, it would be inaccurate to say that the structuralists denounced the formalization of pragmatic concepts altogether. Since they are (refreshingly) explicit about their views on this matter, it is worth quoting their words at length:

Generally speaking, pragmatic aspects of science are more difficult to treat formally than the syntactic and semantical ones. This has led some philosophers to the assertion that pragmatic, and especially diachronic, aspects of science cannot be dealt with in any reasonably precise way - they have to be left forever to the "feelings", "intuitions", and vague metaphors of the analyst. We see no warrant for this romantic view of diachronics. Admittedly, only a small portion of pragmatic concepts may be formalized in a completely satisfactory way. But, some can actually be treated in this way through our set-theoretic tools. And, what is more important, a great deal of the rest can be reconstructed with a high

\footnotetext{
48 Carnap did make use of pragmatics on occasion. In these instances, though, Carnap would use pragmatics in a way that was complementary to-not part of-his logic of science. See Uebel (2013) for a detailed discussion.
} 
degree of precision and systematicity, though not formally (Balzer et al. 1987, pp. 210-211), original italics.

Hence, we see that the structuralists' take on the formalization of pragmatic concepts is a subtle one: not outright placing pragmatic concepts outside the scope of formal analysis, but still acknowledging a 'special problem' regarding the formalization of pragmatic concepts that is not shared by their syntactic or semantic counterparts.

For present purposes, what matters is the following observation:

Observation. Formal philosophers of science (at least within the movements of logical empiricism and Munich structuralism) believed that pragmatic aspects of science could only be analysed partially, or not at all, by the use of formal methods. By extension, this means that these formal philosophers are ill-poised to accommodate reflections on scientific practice.

Let us now consider the role of scientific practice in the contemporary Integrated HPS literature. First, it is important to stress that reflections on the historical aspects of science need not also involve reflections on scientific practice. To see this, we need only look at the early twentieth-century 'intellectual' history of science-for instance in the vein of Koyré (1939). This admittedly straightforward observation serves to highlight the fact that historical reflections on science need not be concerned exclusively with scientific practice.

This preliminary observation, while straightforward, is highly instructive when we consider contemporary work that self-identifies as Integrated HPS. While we should take care to avoid the pitfall of overgeneralization, I would nevertheless venture a claim like the following:

Claim. Many contemporary proponents of Integrated HPS tie this project-be it implicitly or explicitly - to a commitment to practice-based philosophy of science, i.e. the distinctive style of philosophy of science that emerged in the 1980s and '90s (in the wake of the eponymous practice turn) and that puts considerations drawn from scientific practice centre stage. 49

This is not the place to defend this claim at length. Ideally, it would be substantiated by an extensive literature review of the Integrated HPS literature vis-à-vis practicebased philosophy of science. However, since such a review lies well outside the scope of my present discussion, let me just note anecdotally that many of the seminal works in the Integrated HPS scene_e.g. Chang (2004), Steinle (2016), Schickore (2017)_fall squarely within the tradition of practice-based philosophy of science as well. ${ }^{50}$

\footnotetext{
49 There is much more to say about practice-based philosophy of science, though doing so here would take us too far afield. See Soler et al. (2014) for a representative overview.

50 For an example of how the commitment to practice-based philosophy of science tacitly enters into reflections on Integrated HPS: Theodore Arabatzis, in his (2017), considers the "the added historiographical value of engaging with philosophy of science" (ibid., p. 70). Now, this statement of interest seems prima facie neutral with regard to the kind of philosophy of science that is meant. However, Arabatzis swiftly, and tacitly, narrows his scope to "historical accounts of past scientific practice", which-he proposes-may be enriched by philosophical analyses of relevant metascientific concepts like epistemic value, experiment and discovery; all concepts which are strongly associated with practice-based philosophy of science. The fourth metascientific concept whose historiographical value Arabatzis considers
} 
Bringing together our Observation about formal philosophy of science and our Claim about Integrated HPS, we arrive at a possible explanation for why the (perception of a) H/F dichotomy has proved so persistent; an explanation that is, moreover, grounded in disciplinary happenstance. On the one hand, many of the contemporary proponents of Integrated HPS, due to developments in history and philosophy of science qua disciplines, place great stock on engagement with scientific practice. On the other hand, formal philosophers of science-in absence of a pioneer that did for pragmatics what Tarski did for semantics - have always been reluctant to include pragmatic concepts, including concepts related to scientific practice, in the purview of their formal analyses. Formal philosophers, then, could either opt not to engage with the historical dimension of science at all or, alternatively, still engage with the history of science, but only to the extent they do not involve pragmatic concepts in their analyses. In either scenario, however, we see that the resulting formal analyses would be of little interest to the modern Integrated HPS community.

\section{Conclusion}

Let me conclude by summarizing the main points that have been made and reflecting on the prospects for Integrated HFS. In Sect. 1, we encountered the supposed dichotomy between formal and historical philosophy of science. Noting that the validity of the $\mathrm{H} / \mathrm{F}$ dichotomy seems to be assumed rather than explicitly argued for, I presented, in Sect. 2, two possible arguments for a principled H/F dichotomy and argued that, on the subject view of historical philosophy of science, neither of the arguments goes through. Having established that Integrated HFS is viable in principle, we explored what an Integrated HFS might look like in practice. To this end, I presented in Sect. 3 the little-known metascientific research tradition of FMU and argued in Sect. 4 that FMU should - by reasonable criteria of adequacy - be considered a valid example of Integrated HFS. Finally, in Sect. 5, I offered a tentative explanation for why the myth of the H/F dichotomy has proved so persistent.

Where does this leave the project of Integrated HFS? As noted above, there are no convincing arguments (be they principled or practical) against the viability of Integrated HFS. Moreover, we have gained some insight into what obstacles need to be removed in order for Integrated HFS to become a respectable subfield of Integrated HPS. Crucial here is the rehabilitation of 'practice' in formal philosophy of science 51 and a realization, on the side of historical philosophers of science, that a practice-based understanding of science in no way precludes an adherence to formal methods. It is hard to say if, and to what extent, these developments may be brought about in the foreseeable future. I hope the above discussion may, in any case, help pave the way for

Footnote 50 continued

is that of conceptual change. This particular subject matter is, admittedly, not as overtly tied to practice-based philosophy of science as the aforementioned three; see, however, Nersessian (2008).

51 To this end, further exploration of agent-based models of scientific enquiry, as developed in computational philosophy of science (cf. footnote 6), may prove particularly fruitful. An additional avenue of research suggested by this observation is how such agent-based models may be combined with the accounts developed within FMU. 
closer interaction between two important - though all too often disjointed-research communities in contemporary philosophy of science.

In closing, let me note that nothing in the preceding discussion requires that a new framework for doing Integrated HFS is an expansion or modification of the accounts discussed in Sect. 3-although it certainly could be. Moreover, such a new framework need not even proceed in terms of some formalized macro-unit, i.e. it need not be situated within the tradition of FMU—although, again, it certainly could be. The moral, here, is that there need not be only one framework for Integrated HFS. Indeed, not only are formalism and history compatible, they are compatible in potentially many different ways.

Acknowledgements This work was supported by the Tarner Studentship in the Philosophy of Science and the History of Scientific Ideas, held at Trinity College, Cambridge. I would like to thank Jeremy Butterfield, Hasok Chang, Samuel Fletcher, Dunja Šešelja and two anonymous reviewers for helpful comments on this paper. Having said this, any views expressed in this paper (and any shortcomings therein) are completely my own.

\section{Declarations}

Conflict of interest The author declares that they have no conflict of interest

Open Access This article is licensed under a Creative Commons Attribution 4.0 International License, which permits use, sharing, adaptation, distribution and reproduction in any medium or format, as long as you give appropriate credit to the original author(s) and the source, provide a link to the Creative Commons licence, and indicate if changes were made. The images or other third party material in this article are included in the article's Creative Commons licence, unless indicated otherwise in a credit line to the material. If material is not included in the article's Creative Commons licence and your intended use is not permitted by statutory regulation or exceeds the permitted use, you will need to obtain permission directly from the copyright holder. To view a copy of this licence, visit http://creativecommons.org/licenses/by/4.0/.

\section{References}

Arabatzis, T. (2017). What's in it for the historian of science? Reflections on the value of philosophy of science for history of science. International Studies in the Philosophy of Science, 31(1), 69-82.

Baigrie, B., \& Hattiangadi, J. N. (1981). Laudan's problems. Metaphilosophy, 12(1), 85-95.

Balzer, W., Moulines, C. U., \& Sneed, J. D. (1987). An architectonic for science: The structuralist approach. Dordrecht: Reidel.

Barwise, J., \& Feferman, S. (Eds.). (1985). Model-theoretic logics. New York: Springer.

Bolinska, A., \& Martin, J. D. (2020). Negotiating history: Contingency, canonicity, and case studies. Studies in History and Philosophy of Science Part A, 80, 37-46.

Burian, R. M. (2002). Comments on the precarious relationship between history and philosophy of science. Perspectives on Science, 10(4), 398-407.

Caneva, K. L. (2012). What in truth divides historians and philosophers of science? In S. Mauskopf \& T. Schmaltz (Eds.), Integrating History and Philosophy of Science. Springer: Dordrecht. Pages 109-124 of:

Carnap, R. (1939). Foundations of logic and mathematics. Chicago: University of Chicago Press.

Carnap, R. (1950/1962). Logical foundations of probability. Chicago: University of Chicago Press.

Carrier, M. (1988). On novel facts: A discussion of criteria for non-ad-hoc-ness in the methodology of scientific research programmes. Journal for General Philosophyof Science, 19(2), 205-231.

Chang, H. (2004). Inventing temperature: Measurement and scientific progress. Oxford: Oxford University Press. 
Chang, H. (2012). Beyond case-studies: History as philosophy. In S. Mauskopf \& T. Schmaltz (Eds.), Integrating history and philosophy of science (pp. 59-65). Dordrecht: Springer.

Cowan, T. A. (1947). The historian and the philosophy of science. Isis, 38(1), 11-18.

Damböck, C. (2014). Caught in the middle: Philosophy of science between the historical turn and formal philosophy as illustrated by the program of "Kuhn Sneedified". HOPOS: The Journal of the International Society for the History of Philosophy of Science, 4(1), 62-82.

Donovan, A., Laudan, L., \& Laudan, R. (Eds.). (1988). Scrutinizing science: Empirical studies of scientific change. Dordrecht: Kluwer.

Dresow, M. (2020). History and philosophy of science after the practice-turn: From inherent tension to local integration. Studies in History and Philosophy of Science Part A, 82, 57-65.

Dutilh Novaes, C. (2020). Carnap meets foucault: Conceptual engineering and genealogical investigations. Inquiry. https://doi.org/10.1080/0020174X.2020.1860122

Earman, J. (1992). Bayes or bust? A critical examination of Bayesian confirmation theory. Cambridge, MA: MIT Press.

Frey, D., \& Šešelja, D. (2018). what is the epistemic function of highly idealized agent-based models of scientific inquiry? Philosophy of the Social Sciences, 48(4), 407-433.

Friedman, M. (2008). History and philosophy of science in a new key. Isis, 99(1), 125-134.

Gaukroger, S. (1978). Explanatory structures: A study of concepts of explanation in early physics and philosophy. London: Harvester Press.

Giere, R. N. (1973). History and philosophy of science: Intimate relationship or marriage of convenience? The British Journal for the Philosophy of Science, 24(3), 282-297.

Giere, R. N. (1978). Review of progress and its problems by Larry Laudan. The American Historical Review, 83(3), 688-689.

Giere, R. N. (1985). Philosophy of science naturalized. Philosophy of Science, 52(3), 331-356.

Gonzalez, W. J. (2001). Lakatos's approach on prediction and novel facts. Theoria, 16(3), 499-518.

Hintikka, J., Gruender, D., \& Agazzi, E. (Eds.). (1981). Theory change, ancient axiomatics, and Galileo's methodology (Vol. 1). Dordrecht: D. Reidel.

Horsten, L., \& Douven, I. (2008). Formal methods in the philosophy of science. Studia Logica: An International Journal for Symbolic Logic, 89(2), 151-162.

Jansson, L. (2014). Causal theories of explanation and the challenge of explanatory disagreement. Philosophy of Science, 81(3), 332-348.

Jardine, N. (1978). Review: Science as problem-solving. Science, New Series, 199, 4327.

Kockelmans, J. J. (1979). Reflections on Lakatos' methodology of scientific research programs. In G. Radnitzky \& G. Andersson (Eds.), The structure and development of science (pp. 187-203). Dordrecht: D. Reidel.

Kornblith, H. (2016). Philosophical naturalism. In H. Cappelen, T. S. Gendler, \& J. Hawthorne (Eds.), The Oxford handbook of philosophical methodology (pp. 147-158). Oxford: Oxford University Press.

Koyré, A. (1939). Études galiléennes. Paris: Hermann.

Kuhn, T. S. (1962). The structure of scientific revolutions. Chicago: University of Chicago Press.

Kuhn, T. S. (1970). Logic of discovery or psychology of research? In I. Lakatos \& A. Musgrave (Eds.), Criticism and the growth of knowledge (pp. 1-23). Cambridge: Cambridge University Press.

Kuhn, T. S. (1976). Theory-change as structure-change: Comments on the sneed formalism. Erkenntnis, 10(2), 179-199.

Kuukkanen, J.-M. (2009). Rereading Kuhn. International Studies in the Philosophy of Science, 23(2), 217-224.

Kuukkanen, J.-M. (2016). Historicism and the failure of HPS. Studies in History and Philosophy of Science, $55,3-11$.

Lakatos, I. (1970). History of science and its rational reconstructions. PSA: Proceedings of the Biennial Meeting of the Philosophy of Science Association, 1970, 91-136.

Lakatos, I., \& Zahar, E. G. (1976). Why did Copernicus's programme supersede Ptolemy's? In R. S. Westman (Ed.), The Copernican achievement (pp. 354-383). Los Angeles: University of California Press.

Larmore, C. (1981). Review of explanatory structures by Stephen Gaukroger. British Journal for the Philosophy of Science, 32(3), 318-325.

Laudan, L. (1977). Progress and its problems. Berkeley, CA: University of California Press.

Laudan, L. (1981). Science and hypothesis: Historical essays on scientific methodology. Dordrecht: Reidel.

Laudan, L. (1989). Thoughts on HPS: 20 years later. Studies in History and Philosophy of Science Part A, 20(1), 9-13. 
Laudan, L. (1990). Normative naturalism. Philosophy of Science, 57(1), 44-59.

Laudan, L., Donovan, A., Laudan, R., Barker, P., Brown, H., Leplin, J., Thagard, P., \& Wykstra, S. (1986). Scientific change: Philosophical models and historical research. Synthese, 69(2), 141-223.

Lorenzano, P. (2010). Logic and methodology of science: An introduction to the philosophy of science. In P. Lorenzano, H. J. Rheinberger, \& C. D. Galles (Eds.), History and philosophy of science and technology (Vol. I, pp. 1-50). Oxford: EOLSS.

Marcum, J. A. (2015). The evolving notion and role of Kuhn's incommensurability thesis. In W. J. Devlin \& A. Bokulich (Eds.), Kuhn's structure of scientific revolutions-50 years on (pp. 115-134). Heidelberg: Springer.

Masterman, M. (1970). The nature of a paradigm. In I. Lakatos \& A. Musgrave (Eds.), Criticism and the growth of knowledge (pp. 59-90). Cambridge: Cambridge University Press.

Matheson, C., \& Dallmann, J. (2017). Historicist theories of scientific rationality. In E. N. Zalta (Ed.), The Stanford encyclopedia of philosophy, summer (2017th ed.). Stanford: Metaphysics Research Lab, Stanford University.

McMullin, E. (1979). Review: Laudan's progress and its problems. Philosophy of Science, 46(4), $623-644$.

Miller, D. M. (2012). The history and philosophy of science history. In S. Mauskopf \& T. Schmaltz (Eds.), Integrating history and philosophy of science (pp. 29-48). Dordrecht: Springer.

Morris, C. W. (1938). Foundations of the theory of signs. Chicago: University of Chicago Press.

Müller, T. (2010). Formal methods in the philosophy of natural science. In F. Stadler (Ed.), The present situation in the philosophy of science (pp. 111-123). Berlin: Springer.

Musgrave, A. (1979). Problems with progress. Synthese, 42(3), 443-464.

Nersessian, N. J. (2008). Creating scientific concepts. Cambridge, MA: MIT Press.

Nickles, T. (1995). Philosophy of science and history of science. Osiris, 10, 138-163.

Papineau, D. (2021). Naturalism. In E. N. Zalta (Ed.), The Stanford encyclopedia of philosophy, summer (2021st ed.). Stanford: Metaphysics Research Lab, Stanford University.

Pearce, D. (1981). Is there any theoretical justification for a nonstatement view of theories? Synthese, 46(1), $1-39$.

Pearce, D. (1982). Stegmüller on Kuhn and incommensurability. British Journal for the Philosophy of Science, 33(4), 389-396.

Pearce, D. (1986). Incommensurability and reduction reconsidered. Erkenntnis, 24(3), 293-308.

Pearce, D. (1987). Roads to commensurability. Dordrecht: D. Reidel.

Pearce, D., \& Rantala, V. (1983a). Constructing general models of theory dynamics. Studia Logica: An International Journal for Symbolic Logic, 42(3), 347-362.

Pearce, D., \& Rantala, V. (1983b). New foundations for metascience. Synthese, 56(1), 1-26.

Pearce, D., \& Rantala, V. (1984). Scientific change, continuity, and problem solving. Philosophia Naturalis, 21, 389-399.

Pitt, J. C. (2001). The dilemma of case studies: Toward a Heraclitian philosophy of science. Perspectives on Science, 9(4), 373-382.

Popper, K. (1970). Normal science and its dangers. In I. Lakatos \& A. Musgrave (Eds.), Criticism and the growth of knowledge (pp. 25-37). Cambridge: Cambridge University Press.

Price, H. (2008). Two notions of naturalism. Tilburg: René Descartes Lectures.

Rantala, V. (1978). The old and the new logic of metascience. Synthese, 39(2), 233-247.

Rantala, V. (1980). On the logical basis of the structuralist philosophy of science. Erkenntnis, 15(3), 269286.

Salmon, W. C. (1970). Bayes's theorem and the history of science. In R. H. Stuewer (Ed.), Historical and philosophical perspectives of science (pp. 68-86). Minneapolis (MI): University of Minnesota Press.

Salmon, W. C. (1990). Rationality and objectivity in science, or Tom Kuhn meets Tom Bayes. In C. W. Savage (Ed.), Scientific theories (pp. 175-204). Minneapolis, MI: University of Minnesota Press.

Schickore, J. (2011). More thoughts on HPS: Another 20 years later. Perspectives on Science, 19(4), 453481.

Schickore, J. (2017). About method: Experimenters, snake venom, and the history of writing scientifically. Chicago: University of Chicago Press.

Schickore, J. (2018). Larry Laudan's typology for historical methodology and the historical and experimental turns in philosophy of science. HOPOS: The Journal of the International Society for the History of Philosophy of Science, 8(1), 87-107.

Scholl, R. (2018). Scenes from a marriage: On the confrontation model of history and philosophy of science. The Journal of the Philosophy of History, 12(2), 212-238. 
Scholl, R., \& Räz, T. (2016). Towards a methodology for integrated history and philosophy of science. In T. Sauer \& R. Scholl (Eds.), The philosophy of historical case studies (pp. 69-91). Berlin: Springer.

Shapere, D. (1964). Discussion of T. S .Kuhn. The structure of scientific revolutions. Philosophical Review, 73(3), 383-394.

Sneed, J. D. (1971). The logical structure of mathematical physics. Dordrecht: D. Reidel.

Soler, L., Sankey, H., \& Hoyningen-Huene, P. (Eds.). (2008). Rethinking scientific change and theory comparison. Dordrecht: Springer.

Soler, L., Zwart, S., Lynch, M., \& Israel-Jost, V. (Eds.). (2014). Science after the practice turn in the philosophy, history, and social studies of science. Cambridge: Routledge.

Stegmüller, W. (1973). Theorienstruktur und theoriendynamik Probleme und resultateder wissenschaftstheorie und analytischen philosophie (Vol. 2(2)). Berlin: Springer.

Stegmüller, W. (1976). The structure and dynamics of theories. New York (NY): Springer.

Steinle, F. (2016). Exploratory experiments: Ampère, Faraday, and the origins of electrodynamics. English translation by Alex LevinePittsburgh: University of Pittsburgh Press.

Suppe, F. (1977). The search for philosophic understanding of scientific theories. In F. Suppe (Ed.), The structure of scientific theories. Urbana: University of Illinois Press.

Thomason, N. (1992). Could lakatos, even with Zahar's criterion for novel fact, evaluate the copernican research programme? British Journal for the Philosophy of Science, 43(2), 161-200.

Tsou, J. Y. (2015). Reconsidering the Carnap-Kuhn connection. In W. J. Devlin \& A. Bokulich (Eds.), Kuhn's structure of scientific revolutions - 50 years on (pp. 51-69). Heidelberg: Springer.

Turchin, P. (2003). Historical dynamics: Why states rise and fall. Princeton, NJ: Princeton University Press.

Uebel, T. (2013). Pragmatics in carnap and morris and the bipartite metatheory conception. Erkenntnis, 78, 523-546.

Van Benthem, J. (1982). The logical study of science. Synthese, 51(3), 431-472.

Watkins, J. (1970). Against 'normal science'. In I. Lakatos \& A. Musgrave (Eds.), Criticism and the growth of knowledge (pp. 51-58). Cambridge: Cambridge University Press.

Publisher's Note Springer Nature remains neutral with regard to jurisdictional claims in published maps and institutional affiliations. 